\title{
A Study on the Performance Test of Weight Sensor System for Agent Monitoring of Gaseous Extinguishing System
}

\author{
SungHo Hong ${ }^{1, *}$, MoonSoo Choi ${ }^{1}$, DongSuk Kim ${ }^{1}$, JiHyun Kwark ${ }^{1}$ and GoSeop Roh ${ }^{2}$ \\ ${ }^{1}$ Fire Insurers Laboratories of Korea, 1030 Gyeongchung-daero, Ganam-eup, Yeoju-city, Gyeonggi-do, Korea \\ ${ }^{2}$ Jinhwa Engineering \& Construction, 12, Bangbaecheon-ro 4-gil, Seocho-gu, Seoul, Korea \\ *Corresponding author
}

\begin{abstract}
This paper presents a study on the performance test for newly developed weight sensor system for agent monitoring of gaseous extinguishing system. The weight sensor system consists of weight sensor, LCD display, main board, power unit and so on. The performance test is configured to be able to accurately evaluate the performance of the system, and the experimental trial and error is used to set the basic functional test. The output characteristic of weight sensor to be inserted in the weight sensor system is analyzed according to weight variation. Also in order to set basic functional test an experiment is conducted to simulate weight monitoring state using real fire extinguishing agent. In addition to functional test the performance test consists of electric stability test such as insulation resistance test, dielectric strength test, supply voltage variation test and environmental test such as damp heat (steady state) test, variation test and so on. The performance of weight sensor system is verified by this performance test.
\end{abstract}

Keywords-performance test; gaseous extinguishing; monitoring; weight sensor; extinguishing agent

\section{INTRODUCTION}

Gaseous extinguishing system is a term to describe the use of inert gases and chemical agents to extinguish a fire. Broadly speaking, there are two methods for applying an extinguishing agent: total flooding and local application [1][2]. Systems working on a total flooding principle apply an extinguishing agent to a three dimensional enclosed space in order to achieve a concentration of the agent (volume percent of the agent in air) adequate to extinguish the fire. These types of systems may be operated automatically by detection and related controls or manually by the operation of a system actuator. Systems working on a local application principle apply an extinguishing agent directly onto a fire (usually a two dimensional area), or into the three dimensional region immediately surrounding the substance or object on fire. The gaseous extinguishing systems are waterless, deploy quickly and most importantly cleanly without leaving water, particulate or oily residue on high value or irreplaceable assets. Recently gaseous extinguishing system is installed in various places because of above-mentioned advantage.

However, the extinguishing agents of the extinguishing systems are often occurred to natural leakage and leakage caused by long-term neglect aging of the cylinder valve of the extinguishing agent. For this reason, there are cases that do not extinguish the fire due to the lack of the extinguishing agent in real fire [3]. To improve this shortcoming various methods for gaseous extinguishing system has been developed. Especially, monitoring systems of extinguishing agent using weight sensor have been variously developed in Korea. But it is fails to work the performance verification because there is no test method for evaluation of these systems.

In this paper the performance test is suggest for weight sensor system for monitoring of extinguishing agent. It is conducted to determine basic functional test of the performance test. And in order to establish the performance test relevant criteria is analyzed to set the performance test for weight sensor system in this paper.

\section{WeIght Sensor System For AgEnt MONItORING OF GASEOUS EXTINGUISHING SYSTEM}

\section{A. Display Part}

The display part consists of LCD monitor, main circuit board and power unit. The display part is designed to display the output of various sensor output besides weight monitoring. As shown figure I, the communication of display part is used to CAN, PLC and Ethernet to process sensor output. And CPU of $16 \mathrm{bit}-20 \mathrm{MHz}$ is used to compute signal value.

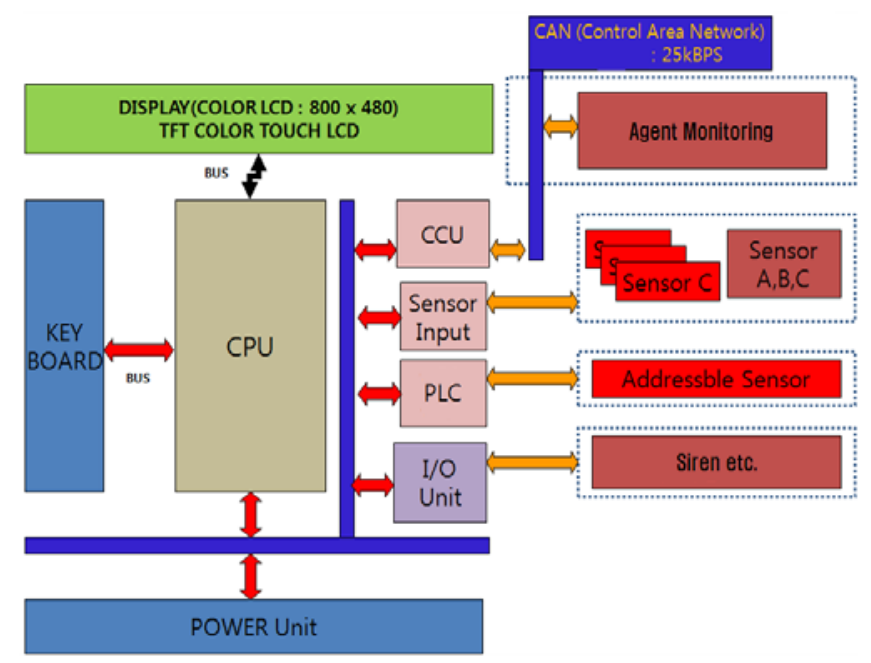

FIGURE I. A SCHEMATIC DIAGRAM OF DISPLAY PART 
The LCD has storage time display, operating On/Off button, activation time displayed in seconds and operating alarm display. Figure II is shown real produced display part.

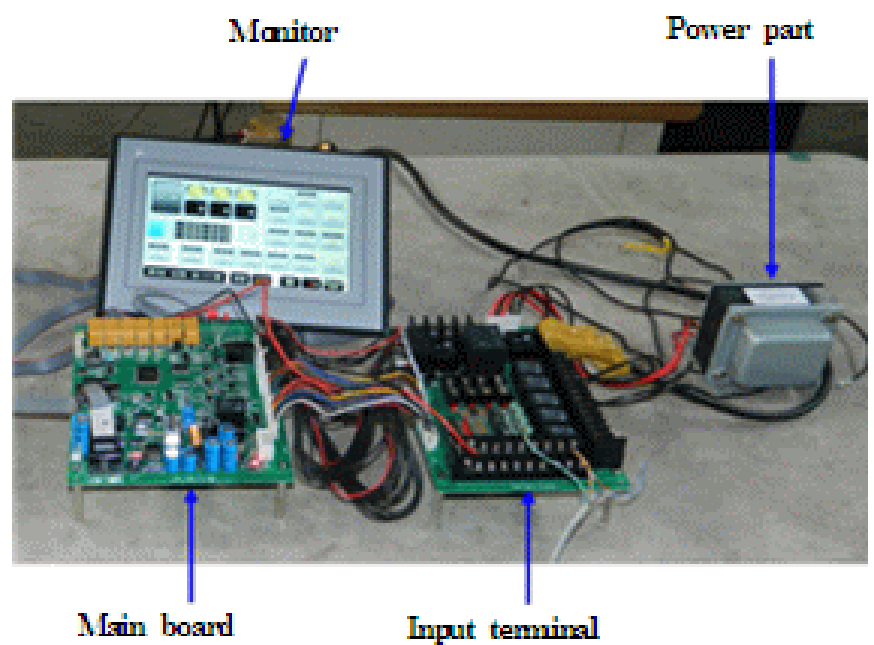

FIGURE II. DISPLAY PART

\section{B. Weight Sensing Part}

The weight sensing is applied to Pascal's principal. That is, the weight indicates the weight in accordance with the $F$ value corresponding to the same output voltage to the changed $\mathrm{W}$ value as shown figure III. Then weight sensing plate is filled by incompressible fluid and to sensing pressure variation of weight sensor is used. Figure IV is shown three dimensional drawing of weight sensing plate.

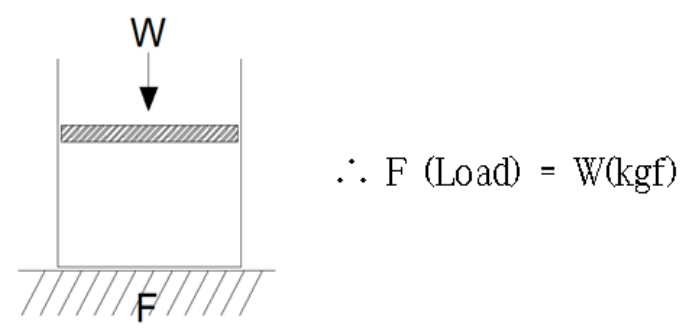

FIGURE III. CONCEPTUAL DIAGRAM OF WEIGHT SENSING

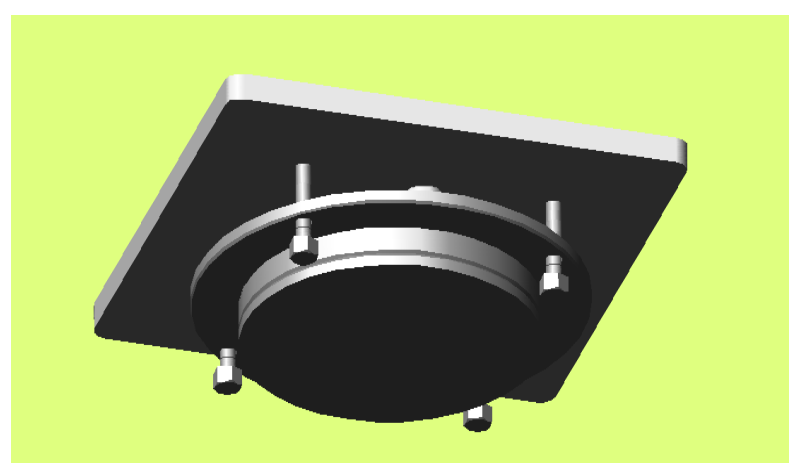

FIGURE IV. THREE DIMENSIONAL DRAWING OF WEIGHT SENSING PLATE
The weight sensing part consists of weight sensor, plate for placing a cylinder of extinguishing agent, incompressible fluid and flexible pipe for fluid transfer. Weight is displayed according to the weight variation of extinguishing agent if is placed the cylinder on the plate.

\section{PERformance Test}

\section{A. Sensor Characteristic Tset}

Sensor characteristic test is to measure the output according to pressure variation. Weight sensor is applied to 5 $\mathrm{V}$ of a DC power supply and to increase pressure in $2 \mathrm{~kg} / \mathrm{cm}^{2}$ using a deadweight tester to measure the output voltage from the pressure sensor.

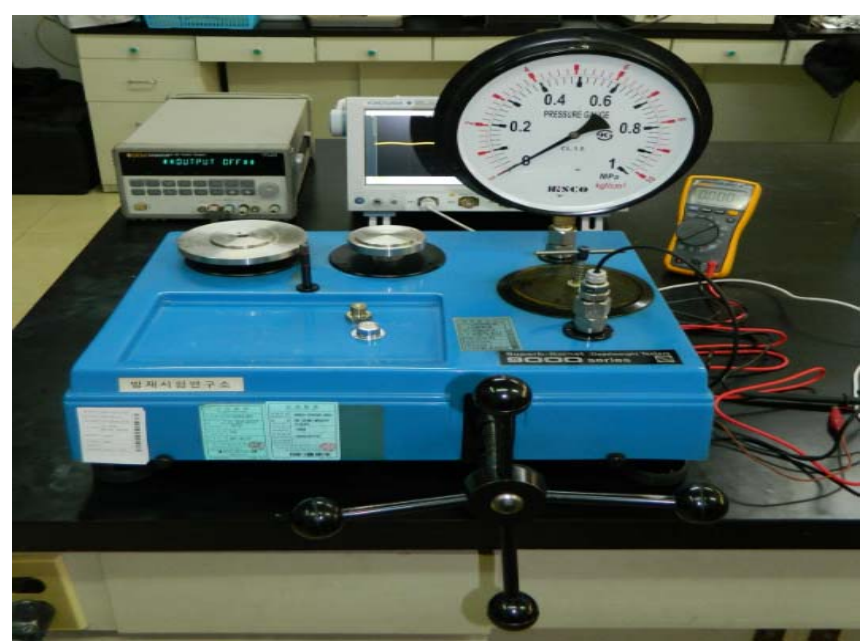

FIGURE V. EXPERIMENTAL SETUP FOR WEIGHT SENSOR

The Output of weight sensor is very constant as shown table I. The deviations of each sample output show $1 \mathrm{mV} \sim 3$ $\mathrm{mV}$. Especially, deviation of sensor output value shown as $\mathrm{mV}$ unit will be able to accurately sensing the fine variation of weight. Based on this output it can be seen that the sensor of sensing of pressure variation can be applied to the weight sensor system.

TABLE I. OUTPUT OF WEIGHT SENSOR

\begin{tabular}{|c|c|c|c|c|}
\hline \multirow{2}{*}{$\begin{array}{c}\text { Pressure } \\
\left(\mathrm{kg} / \mathrm{cm}^{2}\right)\end{array}$} & \multicolumn{4}{|c|}{ Output(V) } \\
\cline { 2 - 5 } & Sample No.1 & Sample No.2 & Sample No.3 & Average \\
\hline 0 & 0.5 & 0.5 & 0.5 & 0.5 \\
\hline 2 & 1.277 & 1.278 & 1.275 & 1.277 \\
\hline 4 & 2.054 & 2.054 & 2.051 & 2.053 \\
\hline 6 & 2.831 & 2.832 & 2.828 & 2.830 \\
\hline 8 & 3.61 & 3.609 & 3.603 & 3.607 \\
\hline 10 & 4.386 & 4.387 & 4.379 & 4.384 \\
\hline
\end{tabular}

\section{B. Functional Test}

Functional test is the most basic test to verify the performance of weight sensor system. The most important consideration of functional test is to verify that the weight sensor system is how to accurately measure the weight. In this paper agent monitoring function of the weight sensor system is verified using real cylinder of extinguishing agent. Placing real 
cylinder of extinguishing agent on plate weight is measured to sensor value output to slowly reducing weight in cylinder. Figure VI is shown functional test for weight sensing. The performance requirement of functional test is constant output according to weight reduction of extinguishing agent.

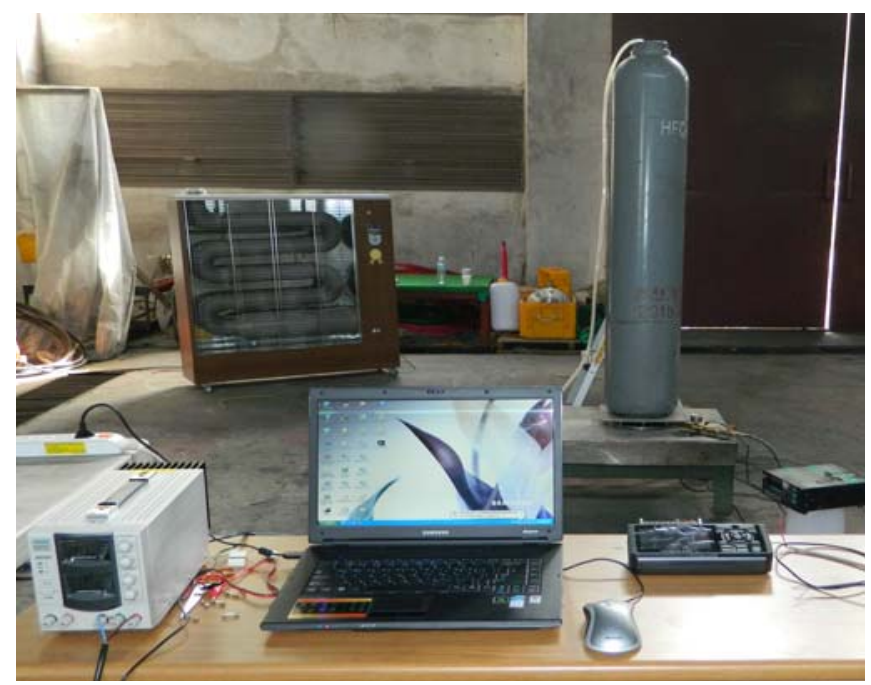

FIGURE VI. FUNCTIONAL TEST FOR WEIGHT SENSING

Figure VII is shown output voltage of weight sensor system varied according to weight reduction. The output voltage is relatively constant, but is not meet requirement. The performance requirement is dotted line in figure VIII. However, this method is very qualitative. There is a possibility that confuse whether conformity of performance requirement or not. So in further research, it is necessary that the quantitative value of the performance requirements is to establish by experimental repetition.

The additional item of functional test is verification of interface of display part. The interface shall be capable of transmitting the occurrence of the signal such as weight abnormality, communication error and so on.

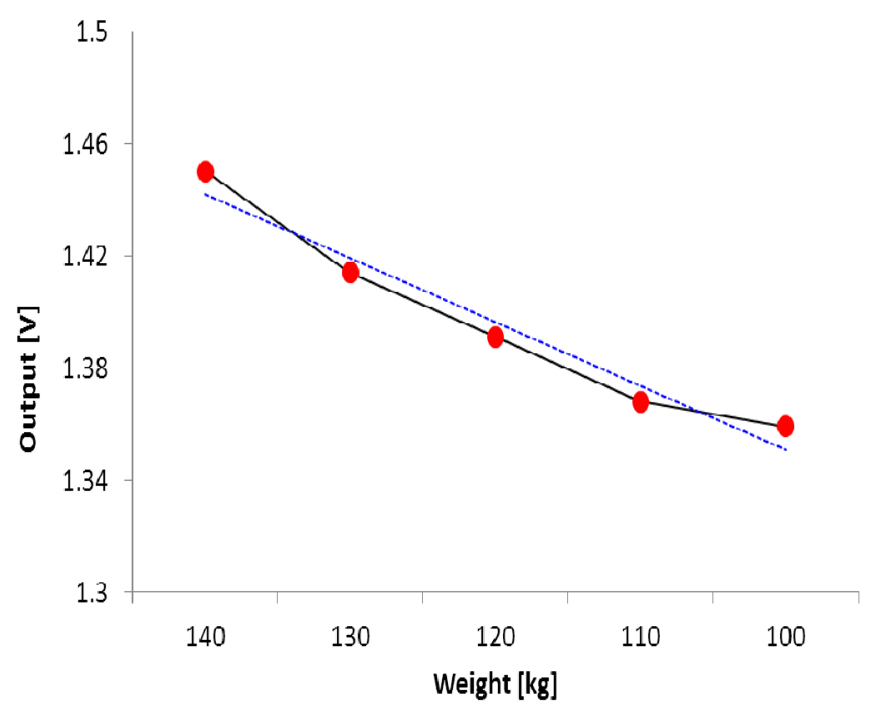

FIGURE VII. OUTPUT ACCORDING TO WEIGHT VARIATION

\section{Supply Voltage Varition Test[4]}

The object of this test is to demonstrate the ability to function correctly over the anticipated range of supply voltage conditions. The weight sensor system shall have no functional abnormalities when supply voltage fluctuation is within the range of $\pm 20 \%$ normal rated voltage

\section{Insulation Resistance Test}

Insulation resistance between insulated resistance terminals and between each terminal and the enclosure shall be $50 \mathrm{M} \Omega$ or more when measured with a DC $500 \mathrm{~V}$ insulating ohmmeter.

\section{E. Dielectric Strength Test}

Detectors shall be capable of withstanding the application of a $60 \mathrm{~Hz}$ alternating voltage of effective $500 \mathrm{~V}$ (in case that normal rated voltage is within the range between $60 \mathrm{~V}$ and 150 $\mathrm{V}, 1,000 \mathrm{~V}$ shall be applied, and in case of over $150 \mathrm{~V}$, the normal rated voltage multiplied by 2 and added by $100 \mathrm{~V}$ ) with wave close to a sine wave for a period of 1 min between insulated terminals and the enclosure.

\section{F. Environmental Test[5]}

- Damp heat, steady

Apply the following severity of conditioning.

-Temperature: $40{ }^{\circ} \mathrm{C} \pm 2{ }^{\circ} \mathrm{C}$

-Relative humidity: $93 \% \pm 3 \%$

-Duration: four days

-Precondition the specimen at the conditioning temperature $\left(40{ }^{\circ} \mathrm{C} \pm 2{ }^{\circ} \mathrm{C}\right)$ until temperature stability has been reached.

-The weight sensor system shall have no functional abnormalities after conditioning.

- Cold

Apply the following severity of conditioning

-Temperature: $0{ }^{\circ} \mathrm{C} \pm 3{ }^{\circ} \mathrm{C}$

-Duration: $16 \mathrm{~h}$

-The weight sensor system shall have no functional abnormalities after conditioning.

- Vibration, sinusoidal

Apply the following severity of conditioning.

-Frequency range: $10 \mathrm{~Hz}$ to $150 \mathrm{~Hz}$

-Acceleration amplitude: $0.981 \mathrm{~m} / \mathrm{s}^{2}\left(0.1 \mathrm{~g}_{\mathrm{n}}\right)$

-Number of axes: three

-Number of sweep cycles per axis: one for each functional condition

-The weight sensor system shall have no functional abnormalities after conditioning.

\section{G. Electromagnetic Compatibility(EMC), Immunity Test}

The following EMC immunity tests shall be carried out in accordance with IEC 61000-4-2 IEC 61000-4-6 [6]-[10].

- Electrostatic discharge

- Radiated electromagnetic fields fields

- Conducted disturbances induced by electromagnetic

- Fast transient bursts 
- Slow high energy voltage surges

TABLE II. SUMMARY OF PERFORMANCE TEST

\begin{tabular}{|c|c|c|}
\hline \multicolumn{2}{|c|}{ Test } & Contents \\
\hline \multicolumn{2}{|c|}{ Functional test } & $\begin{array}{l}\text { Measurement output value according to } \\
\text { reduction of pressure }\end{array}$ \\
\hline \multicolumn{2}{|c|}{ Supply voltage variation test } & Supply of $\pm 20 \%$ of input voltage \\
\hline \multicolumn{2}{|c|}{ Insulation resistance test } & $\begin{array}{l}\text { More than } 50 \mathrm{M} \Omega \text { when measured with a } \\
\text { DC } 500 \mathrm{~V} \text { Insulating Ohmmeter }\end{array}$ \\
\hline \multicolumn{2}{|c|}{ Dielectric strength test } & $\begin{array}{l}\text { A dielectric strength test of } 1000 \mathrm{~V} \text { AC } \\
\text { plus twice the maximum rated voltage }\end{array}$ \\
\hline \multirow{3}{*}{$\begin{array}{l}\text { Environ- } \\
\text { mental test }\end{array}$} & $\begin{array}{l}\text { Damp heat, } \\
\text { steady state }\end{array}$ & $\begin{array}{l}\text { Temperature: } 40{ }^{\circ} \mathrm{C} \pm 2{ }^{\circ} \mathrm{C} \\
\text { Relative humidity: } 93 \% \pm 3 \% \\
\text { Duration: four days }\end{array}$ \\
\hline & Cold & $\begin{array}{l}\text { Temperature: } 0{ }^{\circ} \mathrm{C} \pm 3{ }^{\circ} \mathrm{C} \text { or other } \\
\text { minimum rated temperature } \\
\text { Duration: } 16 \mathrm{~h}\end{array}$ \\
\hline & $\begin{array}{l}\text { Vibration, } \\
\text { sinusoidal }\end{array}$ & $\begin{array}{l}\text { With rated input voltage applied a 4-hour } \\
\text { vertical vibration test of } 0.5 \mathrm{~mm} \text { total } \\
\text { displacement at a linear frequency sweep } \\
\text { of } 10 \text { to } 30 \mathrm{~Hz}\end{array}$ \\
\hline \multirow{5}{*}{\multicolumn{2}{|c|}{$\begin{array}{l}\text { Electromagnetic } \\
\text { compatibility(EMC), } \\
\text { immunity test }\end{array}$}} & Electrostatic discharge \\
\hline & & Radiated electromag-netic fields \\
\hline & & $\begin{array}{l}\text { Conducted disturbances induced by } \\
\text { electromag-netic fields }\end{array}$ \\
\hline & & Fast transient bursts \\
\hline & & Slow high energy voltage surges \\
\hline
\end{tabular}

\section{CONCLUSIONS}

This study suggested on the performance test of newly developed weight sensor system for agent monitoring of gaseous extinguishing system. The performance test consisted of basic functional test, environmental test, and electrical stability test such supply voltage variation test, insulation resistance test, and dielectric strength test.

The functional test was conducted to evaluate weight sensing performance of the weight sensor system. The result showed that is required quantitative criterion rather than qualitative criterion suggested in this paper.

Further research, it is necessary that the quantitative value of the performance requirements is to establish by experimental repetition.

\section{ACKNOWLEDGMENT}

This research was supported by the Next Generation Fire Protection \& Safety Core Technology Development Program funded by the National Emergency Management Agency (2014-NEMA14-029-01020000-2014).

\section{REFERENCES}

[1] Jeong-In Yoon, Jae-Hyuk Choi, "A Development of Methodology for NOVEC Gas Fire Extinguishing System", Journal of the Korean Society of Marine Engineering, Vol.39, No.3, pp. 206-210, March 2015

[2] Bong Sei Son, Hee Woo Kim, "A Study on Percent Agent in Pipe as a Criterion to Evaluate Limitations and Performance of Gaseous Fire Extinguishing Systems, Journal of Korean Institute of Fire Science \& Engineering, Vol.21, No.4, pp 1-11, December 2007
[3] Ku, Jae-Hyun, "A Study on Personal Safety Improvement of the Gaseous Fire Extinguishing System”, Journal of Korean Society Hazard Mitigation, Vol.14, No.3, pp. 193-199, June 2014

[4] FM 3010, Approval Standard for Fire Alarm Signaling Systems, December 2010

[5] ISO 7240-2, Fire detection and alarm systems -- Part 2: Control and indicating equipment, September 2003

[6] IEC 61000-4-2, Electromagnetic compatibility (EMC) - Part 4-2: Testing and measurement techniques - Electrostatic discharge immunity test, December 2008

[7] IEC 61000-4-3, Electromagnetic compatibility (EMC) - Part 4-3 : Testing and measurement techniques - Radiated, radio-frequency, electromagnetic field immunity test, February 2006

[8] IEC 61000-4-4, Electromagnetic compatibility (EMC) - Part 4-4: Testing and measurement techniques - Electrical fast transient/burst immunity test, April 2012

[9] IEC 61000-4-5, Electromagnetic compatibility (EMC) - Part 4-5: Testing and measurement techniques - Surge immunity test, May 2014

[10] IEC 61000-4-6, Electromagnetic compatibility (EMC) - Part 4-6: Testing and measurement techniques - Immunity to conducted disturbances, induced by radio-frequency fields, October 2013 